\title{
ANÁLISE DE RAPD NA IDENTIFICAÇÃO DE CULTIVARES: UMA METODOLOGIA ÚTIL? ${ }^{1}$
}

\author{
ELISEU BINNECK ${ }^{2}$, JORGE LUIZ NEDEL ${ }^{3}$ E ODIR A. DELLAGOSTIN ${ }^{4}$
}

\begin{abstract}
RESUMO - Caracteres morfológicos têm sido utilizados tradicionalmente como assinaturas da identidade e pureza varietal e genética. Esses descritores se constituem em uma base pobre, por ser uma medida indireta da composição genética do material. Uma vez que caracteres moleculares revelam diferenças genéticas mais rapidamente, com maior precisão e sem o obscurecimento causado pelo efeito ambiental, oferecem vantagens significantes em termos de discriminação, confiabilidade, rapidez e custo reduzido. Um método molecular relativamente novo, DNA polimórfico amplificado ao acaso (RAPD), baseado na reação em cadeia da polimerase (PCR), tem sido adotado por alguns pesquisadores envolvidos no desenvolvimento de métodos de identificação de cultivares principalmente por ser uma técnica simples que não requer nenhuma informação prévia sobre seqüências de nucleotídeos do genoma da espécie, além de ser bastante acessível e de custo relativamente baixo. Mas, infelizmente, a análise de RAPD apresenta sérios problemas, principalmente em relação à reprodutibilidade e caracterização da homologia dos produtos. Se esses problemas podem ser efetivamente resolvidos então a análise de RAPD pode se tornar um método eficiente e aplicável, mas talvez o investimento em tempo e dinheiro seja mais útil no desenvolvimento e adaptação de técnicas mais promissoras. Há um grande volume de publicações sobre a técnica de RAPD na literatura, todas evidenciando o mesmo problema: a variabilidade inerente aos produtos de amplificações com primers decâmeros limita a sua utilização na indústria e em programas de certificação. O objetivo deste trabalho foi discorrer sobre a eficiência da técnica de RAPD na identificação de cultivares, ressaltando as suas vantagens e limitações.

Termos para indexação: DNA polimórfico amplificado ao acaso (RAPD), reprodutibilidade, marcadores moleculares, PCR.
\end{abstract}

\section{RAPD ANALYSIS ON CULTIVAR IDENTIFICATION: A USEFUL METHODOLOGY?}

\begin{abstract}
Morphological characters have traditionally been used as signatures of varietal identity and purity. Because provide an indirect means of assessing genetic composition, those characters provide a poor base for measures of genetic identities. However, molecular characters that more quickly and accurately reveal genetic differences without the obscurance of environment provide significant advantages in discrimination, reliability, timeliness and reduced cost. A relatively new molecular method, Random Amplified Polymorphic DNA (RAPD), that are based on Polymerase Chain Reaction (PCR), whose simplicity, low cost, accessibility and no require of previous information about nucleotide sequence of genome from the species have encouraged the application by researchers involved in the development of methods for cultivar identification. Unfortunately, the RAPD analysis presents serious problems on reproducibility and homology knowledge of products. If these problems can be effectively overcome then RAPD analysis may become an effective and applicable method, but perhaps the investment in time and money be more useful on the development and adaptation of more promissory techniques. There is
\end{abstract}

\footnotetext{
Aceito para publicação em 31.12.2001; parte da tese de Doutorado apresentada pelo primeiro autor a UFPel, Pelotas, RS.

${ }^{2}$ Eng $^{\circ}$ Agr $^{\mathrm{o}}$, Dr., Embrapa Soja, Laboratório de Biotecnologia, Cx. Postal 231,86001-970, Londrina-PR; e-mail: binneck@cnpso.embrapa.br
}

${ }^{3}$ Prof. Titular, PhD., Depto. de Fitotecnia, FAEM/UFPel, Cx. Postal 354 96010-970, Pelotas-RS; e-mail: jlnedel@ufpel.tche.br

${ }^{4}$ Prof. Adjunto, PhD., Centro de Biotecnologia, Depto. de Biologia, UFPel/ FAEM; e-mail: odirad@terra.com.br 
considerable work in the literature on this method. All suffer from say the same problem. The inherent variability of the product from amplifications whit decamer primers limits its utility to industry and certification programs. The objective of this work was discuss about the RAPD analysis efficiency on cultivar identification, showing the vantages and limitations of the technique.

Index terms: Random amplified polymorphic DNA(RAPD), reproducibility, molecular markers, PCR.

\section{INTRODUÇ̃̃O}

O procedimento mais amplamente usado para a identificação de cultivares, monitoramento da pureza genética e descrição de novas cultivares, tem sido, e continua sendo, a comparação de descritores morfológicos das plantas no campo. Esses caracteres se constituem em uma base pobre para medir a identidade, por ser uma medida indireta da composição genética do material. Por isso, é de valor significante para a indústria de sementes o desenvolvimento e adaptação de novas tecnologias que aprimorem o sistema de identificação e avaliação da pureza de lotes de sementes, sobretudo utilizando métodos que acessem diretamente a informação genética. Métodos moleculares têm maior poder discriminatório e medem a composição genética mais diretamente do que os métodos morfológicos. Uma técnica relativamente nova, a análise de Random Amplified Polymorphic DNA (RAPD; Williams et al., 1990), tem sido considerada promissora para esse intento (Smith \& Chin, 1992; Weeden, 1992; Ko et al., 1994; Multani \& Lyon, 1995 e Smith, 1995).

A análise de RAPD é uma derivação do processo de PCR que envolve a amplificação simultânea de vários locos anônimos do genoma, utilizando um único primer (oligonucleotídeo) decâmero de seqüência arbitrária (Williams et al., 1990 e 1993 e Welsh \& McClelland, 1990). A técnica foi desenhada para detectar mudanças unitárias de bases (Williams et al., 1990) em locos distribuídos em toda a extensão do genoma (Williams et al., 1993), com aplicações no mapeamento genômico (Williams et al., 1990) e "fingerprinting" (Welsh \& McClelland, 1990). A denominação RAPDs é usada para denotar os marcadores moleculares gerados pelo método de RAPD. O mesmo método, com pequenas variações no comprimento e concentração do primer usado na amplificação mediada pela DNA polimerase e na separação e detecção dos fragmentos, foi também originalmente descrito com as denominações Arbitrarily Primed - Polimerase Chain Reaction (AP-PCR; Welsh \& McClelland, 1990) e DNA Amplification Fingerprinting (DFA); Caetano-Anollés et al., 1991). Características atrativas como a possibilidade de se obter um grande número de marcadores genéticos sem qualquer informa- ção prévia sobre seqüências de nucleotídeos do genoma da espécie, o baixo custo, rapidez, simplicidade e velocosdade na aquisição dos dados (Ferreira \& Grattapaglia, 1996), levaram os pesquisadores a utilizar amplamente o método, especialmente em análises filogenéticas, "fingerprinting" e mapeamento genômico, empregado-o muitas vezes como uma panacéia na busca de marcadores moleculares. Sendo indicado como um método possivelmente importante em programas de identificação de cultivares (Weeden, 1992; Ko et al., 1994; Multani \& Lyon, 1995; Smith, 1995 e Smith \& Register, 1998), várias tentativas têm sido feitas buscando a sua adaptação para esse fim (Beyermann et al., 1992; McDonald et al., 1994; Ko et al., 1994; Mailer et al., 1994; Multani \& Lyon, 1995; Wolff et al., 1995; McDonald, 1995; Gallego \& Martinez, 1996; Jianhua et al., 1996a-b; Ford \& Taylor, 1997; Meng et al., 1998; Marcos-Filho \& McDonald, 1998; Meng et al., 1998 e Noli et al., 1999). No entanto, parece que a simplicidade da técnica tem obscurecido a necessidade de dar significado aos produtos gerados. Existem sérias limitações em relação à reprodutibilidade dos resultados dentro do laboratório e entre laboratórios (Penner, 1996), além da falta de entendimento da interação complexa que parece ocorrer durante os eventos de anelamento do primer e subseqüente amplificação (Caetano-Anollés et al., 1992), tornando difícil explicar a informação biológica dos marcadores RAPD. Esta revisão tem por objetivo discutir o valor da análise de RAPD para fins de identificação de cultivares, considerando a base genética - até o que se conhece - da técnica, as suas vantagens e desvantagens, sucessos encontrados na identificação de cultivares, análise estatística dos dados gerados e perspectivas para o futuro.

Base genética dos RAPDs - a análise de RAPD é baseada na premissa de que um primer de alguma seqüência aleatória, suficientemente curto, será, por tentativa, complementar a algumas seqüências alvo, distribuídas ao longo do genoma. Os locos que apresentam duas seqüências alvo em fitas opostas com orientação e espaçamento adequado são amplificados pelo processo de PCR. Diferentes fragmentos amplificados representam diferentes locos e, sendo de diferentes comprimentos, podem ser separados e distinguidos por 
eletroforese (Tingey et al., 1992). Embora algumas evidências empíricas mostrem que para determinadas condições experimentais o padrão de bandas de DNA gerado é único e "reproduzível" (Arribas et al., 1997), os parâmetros que governam os eventos de amplificação na análise de RAPD são bastante complexos e ainda não são totalmente compreendidos (Thormann \& Osborn, 1992; Ferreira \& Grattapaglia, 1996 e Hansen et al., 1998).

Os polimorfismos de RAPD parecem ser resultados de vários processos, incluindo substituições de nucleotídeos que criam ou apagam sítios de homologia com o primer, formação de estruturas secundárias entre sítios homólogos e inserção, deleção ou inversão tanto dos sítios de ligação com o primer como seqüências entre esses sítios (Williams et al., 1990 e Tingey et al., 1992). Também, o efeito de substituições de nucleotídeos parece depender da posição de reconhecimento com o primer, sendo mais crítico o pareamento perfeito especialmente na região 3' do primer (Ferreira \& Grattapaglia, 1996), a partir da qual a polimerização inicia. Somado ao polimorfismo em tamanho dos fragmentos amplificados existe o polimorfismo referente à intensidade, no entanto, esse parâmetro normalmente não é utilizado devido à sua grande instabilidade. A variação na intensidade das bandas tem sido atribuída a diferenças no número de cópias amplificadas do fragmento, causadas pela competição entre produtos no processo de PCR, heterozigozidade e combinação parcial do primer com o sítio. Esses poliforfismos são detectados através da presença ou ausência de bandas em gel de eletroforese e podem ser convertidos em dados de homologia entre genótipos. Os sítios de homologia dos primers são distribuídos, teoricamente, em todo o genoma (Williams et al., 1990 e 1993) e o polimorfismo nessas regiões resulta em diferentes produtos amplificados (Tingey et al., 1992). Outras particularidades sobre a base genética dos marcadores RAPD são apresentadas ao longo das explanações que seguem.

O que se busca em um método para identificação de cultivares - exaustivamente, tem sido buscado um método ideal para identificação de cultivares. Esse método deveria apresentar pelo menos seis atributos (Wrigley \& Batey, 1995): (i) ausência de efeito ambiental e do estádio de desenvolvimento; (ii) alto grau de discriminação entre genótipos e baixo dentro do genótipo, ou seja, deve permitir alto grau de polimorfismo, mas não deve ser excessivamente detalhista a ponto de mostrar muita variação intravarietal; (iii) rapidez e facilidade de execução, ou seja, não deve exigir grande especialização do técnico mas deve permitir a obtenção dos resultados em alguns minutos; (iv) objetividade, isto é, não deve sofrer variação de laboratório para laboratório e dentro do laboratório ou entre laboratoristas, oferecendo resultados inequívocos; (v) ligação com informações sobre caracteres qualitativos, possibilitando acessar características de qualidade relacionadas com a utilização industrial e comercial da espécie; (vi) possibilite a utilização de testes estatísticos objetivos para detectar misturas e o coeficiente de similaridade entre genótipos. Muitas tentativas sem sucesso têm sido feitas para contemplar essas exigências através de marcadores RAPD, embora a análise de RAPD apresente uma série de atrativos (Williams et al., 1993 e Penner, 1996), razão pela qual vem sendo amplamente utilizada. Infelizmente a simplicidade técnica da análise de RAPD parece ter obscurecido as dificuldades de entender os resultados (Hillis, 1994), o que tem merecido severas críticas (Skroch \& Nienhuis, 1995 e Karp \& Edwards, 1997).

Vantagens - a possibilidade de investigar polimorfismos moleculares no DNA sem a necessidade restritiva do sequenciamento não se constitui mais uma vantagem para várias espécies, dado o grande volume de seqüências hoje conhecidas. Outro benefício promulgado é que a análise de RAPD permite identificar cultivares ao nível de DNA sem a necessidade de que as seqüências polimórficas sejam expressadas no fenótipo (proteínas, características morfológicas, metabólitos secundários, etc. Eis um ponto negativo da técnica, como vimos no item anterior. De forma geral algumas vantagens podem ser citadas: (i) fragmentos amplificados pela técnica de RAPD têm revelado polimorfismos entre muitos genótipos diferentes e várias técnicas específicas têm sido publicadas para diferentes espécies; (ii) custo relativamente baixo (Ferreira \& Grattapaglia, 1996), após feita a seleção dos primers e otimização do protocolo; (iii) os RAPDs levantam informações de um grande número de locos de, teoricamente, todo o genoma; (iv) independe de grandes quantidades de DNA genômico relativamente puro (Tingey et al., 1992); (v) muitos marcadores são gerados em pouco tempo; (vi) não requer experiência aprofundada em biologia molecular e instalações sofisticadas de laboratório (Ferreira \& Grattapaglia, 1996). Comparando com métodos tradicionalmente utilizados para determinação da pureza genética e identificação de cultivares, (McDonald, 1995) defende cinco vantagens da utilização de RAPDs: (i) os marcadores RAPD proporcionam grande potencial para a discriminação de cultivares já que a composição de nucleotídeos de um gene está sendo diretamente determinada em vez do produto da expressão do gene, como uma enzima; (ii) a versatilidade da análise de RAPD é maior do que da eletroforese de proteína. Mais de 700 "primers" são disponíveis, em comparação com aproxi- 
madamente 20 sistemas enzimáticos; (iii) a análise de RAPD não possui o potencial de risco à saúde humana e o dano ambiental associados com radioisótopos utilizados na maioria das outras tecnologias de DNA, como a técnica de RFLP (Restriction Fragment Length Polymorphism; polimorfismo no comprimento de fragmentos de restrição); (iv) a análise de RAPD requer os mesmos equipamentos gerais e qualidade profissional que a técnica de eletroforese de proteína. Apenas alguns equipamentos adicionais são necessários, como termociclador; (v) o custo e o tempo para uma análise completa de RAPD é equivalente aos protocolos atuais de eletroforese de proteínas.

Limitações - um número de aspectos negativos fazem da análise de RAPD uma técnica difícil de ser padronizada, como a variabilidade nos resultados mesmo dentro de um laboratório, além de outras inconveniências. Os seguintes fatores são objetos de consideráveis discussões sobre a validade da técnica: (i) competição entre produtos; (ii) reprodutibilidade; (iii) homologia dos produtos; (iv) estrutura do primer; (v) dominância; (vi) formação de heteroduplex; (vii) variação alélica e (viii) amostragem genômica.

Competição entre produtos - Em torno de 15\% de erros tem sido encontrado devido à competição, para bandas polimórficas, tanto em genomas de alta como de baixa complexidade (Halldén et al., 1996). A competição entre diferentes segmentos de DNA amplificados na análise de RAPD tem sido classificada como o erro mais sério (Williams et al., 1993 e Halldén et al., 1996). Fenômeno este, em que uma banda RAPD amplificada com sucesso num genótipo não é detectada em outro, pode resultar em interpretações incorretas. Um dos motivos seria o anelamento do primer a regiões não inteiramente homólogas (Williams et al., 1990). Tal competição pode ocorrer, teoricamente, em muitos níveis diferentes; entre sítios dentro de um genoma, entre genomas e entre genótipos (Heun \& Helentjaris, 1993). Numa análise de competição entre genomas de soja e cianobactérias, os quais foram inicialmente misturados (Williams et al., 1993) verificaram que todas as amplificações detectáveis eram de soja, mesmo quando foi utilizado um excesso molar de 460 vezes do genoma de cianobactéria. Os primers utilizados são curtos e por isso possuem complementaridade com muitas regiões do genoma, resultando na amplificação não específica de sítios onde não há flanqueamento próximo o suficiente para formar um fragmento amplificado. Esses sítios competem por substrato (dNTP) e enzima (DNA polimerase) durante a reação em cadeia da polimerase (PCR), resultando em bandas de intensidades distintas e instáveis. A intensidade da banda e a sua estabilidade se tornam, teoricamente, um reflexo dire- to do grau de competitividade do sítio. Essa competitividade varia com fatores como complementaridade ao primer e presença de estruturas secundárias no DNA molde.

Reprodutibilidade - as limitações da análise de RAPD têm sido reconhecidas e análises detalhadas dos produtos RAPD através de Southern blotting e experimentos com enzimas de restrição, e análises da origem genômica e classe de DNA têm sido sugeridas para dar credibilidades aos resultados.

A pobre reprodutibilidade dos resultados, tanto dentro do laboratório como entre laboratórios, tem sido objeto de vários estudos (Skroch et al., 1992; Weeden, 1992; Devos \& Gale, 1992; Penner et al., 1993; Skroch \& Nienhuis, 1995; Penner, 1996 e Hansen et al., 1998). Variações dramáticas nos produtos da análise de RAPD podem resultar de mudanças sutis em vários parâmetros como concentração de DNA, temperatura de anelamento, termociclador, qualidade e concentração do primer, concentração de magnésio, tipo, qualidade e concentração da DNA polimerase, concentração de primer em relação ao DNA molde e precisão na pipetagem (Welsh \& McClelland, 1990; Tingey et al., 1992; Fritsch et al., 1993; Ellsworth et al., 1993; Rafalski et al., 1994; This et al., 1997; Rafalski, 1997 e Hansen et al., 1998). Especialmente crítica é a temperatura de anelamento; abaixo de $36^{\circ} \mathrm{C}$, mudanças da ordem de $1^{\circ} \mathrm{C}$ podem resultar na amplificação de um espectro inteiramente diferente de fragmentos (Penner, 1996). Segundo o mesmo autor, a concentração relativa de todos os reagentes da reação de PCR pode afetar dramaticamente a reprodutibilidade dos resultados. Fatores isolados são mais facilmente controlados, mas quando um número de fatores interage no processo, o controle de variações é altamente delicado e requer um grande esforço na adequação dos protocolos para cada situação específica. Entre laboratórios, a variação dos resultados é ainda mais impressionante. Num estudo feito por (Penner et al., 1993), para verificar se um polimorfismo identificado através da análise de RAPD em um laboratório pode ser identificado em outro laboratório, cinco primers que amplificaram RAPDs entre duas cultivares de aveia foram distribuídos entre seis laboratórios. Diferenças significativas foram observadas nas amplitudes de comprimentos dos fragmentos amplificados nos diferentes laboratórios participantes. A re-extração do DNA, repetição das amplificações e a inclusão de controles disponíveis para checar a reprodutibilidade e a ausência de contaminação pode melhorar a confiabilidade dos resultados, mas se o erro é devido à competição a replicação do experimento não melhora a situação (Halldén et al., 1996). O DNA de algumas espécies tende a ser degradado rapidamente quando as células são destruídas no processo de extração, como exemplo do trigo 
(Penner, 1996). A degradação pode resultar na alteração do resultado da análise.

É necessário estabelecer um balanço entre o número máximo de fragmentos amplificados com cada primer e a reprodutibilidade dos resultados. A otimização das condições de amplificação para se chegar a um balanço aceitável é, na maioria das vezes, um trabalho muito tedioso e dificilmente são encontradas condições decisivas.

Homologia - a homologia entre fragmentos RAPD é mais freqüentemente baseada no fato de que produtos que migram para a mesma posição no gel são idênticos, formando bandas ditas monomórficas, que representariam fragmentos de mesmo tamanho em pares de bases e as mesmas seqüências nas extremidades onde o primer iniciou a amplificação. Produtos assim considerados do mesmo tamanho podem ser não homólogos por duas razões possíveis: (i) limitações na resolução do gel; (ii) convergência de tamanho, devido a deleções ou inserções entre os sítios de ligação dos primers em locos distintos, gerando polimorfismos ambíguos (Williams et al., 1990 e Thormann \& Osborn, 1992).

A resolução das bandas é geralmente baixa nos géis de agarose; produtos de diferentes tamanhos podem migrar para aparentemente a mesma posição no gel. Embora a habilidade de discriminação das bandas possa ser consideravelmente melhorada pela separação dos produtos RAPD utilizando uma combinação de coloração com prata e gel de poliacrilamida (Caetano-Anollés, 1997b), ou com DGGE (eletroforese em gel desnaturante) (Dweikat \& MacKenzie, 1997 e Dweikat \& Mackenzie, 1997), fica difícil manter uma boa repetibilidade dos RAPDs, é mais difícil trabalhar com géis desnaturantes e a discriminação pode ainda ser incompleta (Smith, 1995). Os problemas de homologia em RAPDs pode ser resolvido em alguns casos pela utilização de sistemas aprimorados de resolução dos fragmentos e levando a um detalhado entendimento de cada um dos produtos e a combinação com Southern blotting e estudos de enzimas de restrição e ultimamente análises de seqüências de produtos RAPD individuais (CaetanoAnollés, 1997a). Mesmo esses procedimentos podem não clarear esta questão.

Estrutura do primer - a técnica é altamente sensível a alterações nas condições de amplificação, impurezas no DNA, qualidade e concentração da enzima DNA polimerase e dos reagentes utilizados. A utilização de primers não específicos e curtos aumenta essa sensibilidade. Além disso, existe uma restrição para que os primers possuam 60 a $70 \%$ de GC (guanina e citosina) (Williams et al., 1993). O alto conteúdo de GC nos primers para a análise de RAPD é necessário para que se possa utilizar baixas temperaturas de anelamento (bai- xa estringência) (Rafalski et al., 1994 e Ferreira \& Grattapaglia, 1996), o que resulta num certo grau de imperfeição no anelamento (Williams et al., 1990) e é consistente com a observação de que o número de produtos amplificados é positivamente correlacionado com o conteúdo de GC dos primers (Caetano-Anollés et al., 1991 e Ferreira \& Grattapaglia, 1996). O anelamento dos primers com regiões não absolutamente homólogas possibilitada pelo alto conteúdo de GC significa que há a possibilidade de que diferentes primers se liguem a um mesmo sítio e que sítios diferentes hibridizem com um mesmo primer. Então os produtos de diferentes primers podem ser idênticos ou interdependentes. Sabe-se que o conteúdo de GC não é homogeneamente distribuído no genoma das plantas (Moore \& Gustafson, 1997), sendo assim, a análise de RAPD estaria examinando preferencialmente as regiões ricas em GC.

Dominância - a leitura direta dos RAPDs em géis com brometo de etídio, implicitamente assume que os marcadores RAPD são dominantes (Williams et al., 1990 e Tingey et al., 1992), isto é, a presença de cada marcador é analisada pela presença (1) ou ausência (0) da banda no gel, e, portanto, homozigotos dominantes $(1 ; 1)$ e heterozigotos $(1 ; 0)$ são indistinguíveis um do outro. A detecção dos segmentos RAPD não tem sensibilidade suficiente para discriminar os dois casos, havendo grande probabilidade de que cultivares puras apareçam como mistura. Por exemplo, num programa de melhoramento tradicional uma cultivar melhorada de um cereal diplóide pode ser selecionada até o $\mathrm{F}_{6}$, onde um marcador RAPD recessivo, que era expresso no $\mathrm{F}_{1}$ original heterozigoto, pode ser expresso como homozigoto recessivo numa planta em $64\left(1 / 2^{6}\right)$, e confundido como mistura na cultivar pura. Dificilmente o material chega a total homozigoze. Os testes de distinguibilidade, uniformidade e estabilidade (DUS), portanto, precisariam tomar essa heterogeneidade em conta na definição da cultivar, particularmente se as diferenças nos RAPDs não têm relação com os caracteres fenotípicos observados no programa de melhoramento .

Formação de heteroduplex - uma potencial fonte de erro nos resultados da análise de RAPD é a formação de heteroduplex entre seqüências homólogas (Ayliffe et al., 1994 e Novy \& Vorsa, 1996a).

Variação alélica - a visualização direta dos produtos RAPD assume que existem somente dois alelos (1 ou 0; presença ou ausência do produto) por loco. A falta de um alelo pode ser resultante de diferentes eventos. Então, não existe um meio de identificar alelos ou as suas combinações em diferentes locos, significando que o modelo alelo como caractere não é apropriado para a análise de dados de RAPD. 
Amostragem genômica - a análise de RAPD amostraria aleatoriamente todo o genoma da planta, nuclear, mitocondrial ou do cloraplasto, e ainda variando entre as regiões altamente repetitivo, moderadamente repetitivo ou cópia única (Williams et al., 1990 e Williams et al., 1993). Infelizmente existe pouca informação a respeito da distribuição da complexidade dos genomas e dos locos RAPD nos genomas. Em Eucalyptus, por exemplo, tem-se verificado que acima de 50\% dos fragmentos RAPD amplificados pertencem a regiões de cópia única ou baixo número de cópias. Essa proporção está bem acima da esperada, considerando que aproximadamente 80\% do genoma de Eucalyptus deve se constituir de DNA repetitivo (Grattapaglia \& Sederoff, 1994).

Análise dos dados - admite-se que a presença de um marcador RAPD é bem mais informativa do que a ausência (Skroch et al., 1992). A presença de um marcador em mais de um indivíduo significa que os indivíduos partilham a mesma seqüência nos sítios de hibridização com o primer e que estes sítios são separados pelo mesmo número de pares de bases. A ausência de um fragmento em dois ou mais indivíduos, no entanto, não evidencia o mesmo nível de homologia, isto é, a falha na amplificação do fragmento pode ser devida a mudanças na seqüência de anelamento do primer, adições ou deleções de DNA entre os sítios de anelamento (Williams et al., 1990), ou ainda um maior nível de competição por outros fragmentos amplificados (Thormann \& Osborn, 1992 e Penner, 1996). Para a análise dos dados de um marcador molecular, o primeiro passo é a comparação dos produtos. Para isso, é importante definir quais parâmetros serão considerados: (i) presença (1) ou ausência (0) do fragmento (denotadas pela presença ou ausência da banda) (Skroch et al., 1992); ou (ii) levando em consideração a intensidade. Os dados de RAPD são comumente comparados com base na presença ou ausência do fragmento, não sendo levada em conta a intensidade devido à acentuada variabilidade desse parâmetro. O planejamento de como os eletroforegramas de RAPD serão comparados, embora raramente detalhado nos trabalhos, constitui uma etapa importante por causa dos problemas de reprodutibilidade associados com a técnica. Sugere-se que os perfis de RAPD sejam comparados numa base conservativa, isto é, devem ser considerados (i) somente produtos em uma determinada faixa de tamanho e (ii) somente produtos de alta intensidade e que mostrem grande reprodutibilidade comparada aos produtos de menor intensidade. Com tais procedimentos, enquanto reduz-se número de produtos habilitados para comparação, é possível aumentar a confiabilidade dos resultados.
As bandas comuns são comparadas como presentes ou ausentes e convertidas em dados ( 1 ou 0 , respectivamente), os quais são utilizados na análise de comparação entre os genótipos. O método mais amplamente usado para analisar dados de RAPD, embora inadequado devido aos problemas de homologia (Karp \& Edwards, 1997), tem sido o cálculo de medidas de similaridade utilizando métodos como: coeficiente de Nei e Li, (NL; Nei \& Li, 1979), que mede a probabilidade de um produto amplificado em uma amostra também ser amplificado em outra; coeficiente de Jaccard (J; Jaccard, 1908), que mede a proporção de produtos presentes nos dois perfis de RAPD; coeficiente de concordância simples (SMC; Sneath \& Sokal, 1973), que mede a proporção de produtos cuja presença ou ausência são comuns entre os dois perfis de RAPD e coeficiente de Dice (D; Dice, 1945), muito similar ao coeficiente de Jaccard, mas dá mais peso às bandas que coincidem nos dois genótipos. Alguns autores utilizam medidas de dissimilaridades, o que pode acarretar um erro ainda maior. Essas medidas de similaridade tornam possível estimar a proximidade genética das cultivares. Todas as comparações possíveis entre os genótipos são utilizadas para construir uma matriz de similaridades e analisadas utilizando um método de agrupamento. Os métodos de agrupamentos mais usados são UPGMA (Unweighted Pair-Group Method using Aritmetic Average; média das distâncias) e Neighbor Joining (vizinho mais próximo) (Saitou \& Nei, 1987). UPGMA é provavelmente o método mais freqüentemente utilizado. Os dados também podem ser submetidos a uma análise de componentes principais (PCA; Principal Component Analysis), de forma que os genótipos podem ser representados como pontos em duas ou três dimensões. Essa análise é muito útil para uma inspeção visual do distanciamento entre os genótipos. A análise de componentes principais é, matematicamente, o método de agrupamento mais genuíno e é um excelente método para discriminar entre dois a cinco grupos. Entretanto, este método é limitado para muitos grupos, uma vez que as primeiras três dimensões do sistema multidimensional geralmente não permite uma representação satisfatória de estruturas mais complexas. Infelizmente as medidas de similaridade são baseadas em suposições que podem não ser encontradas em dados de RAPD. Por exemplo, no caso do coeficiente de concordância simples (SMC) todas as bandas coincidentes (ambas as presentes e as ausentes) são levadas em consideração, mesmo que as razões por que os produtos RAPD estão ausentes não sejam conhecidas. Essa suposição não é feita pelos coeficientes de Jaccard (J) e de Nei e Li (NL), mas há problemas no entendimento da homologia entre produtos. 
Embora não exista um consenso sobre a validade dos dados RAPD para esse tipo de análise, algumas discussões são feitas sobre qual seria a medida de similaridade mais apropriada para ser usada com marcadores RAPD (Duarte et al., 1999). Alguns autores preferem utilizar medidas de similaridade que excluem ausências em comum, como J e NL (Kazan et al., 1993).

As limitações dos marcadores RAPD, no entanto, põem em movimento investigações em busca de outros tipos de dados moleculares. Nos últimos anos um crescente número de técnicas moleculares tem se tornado disponível. Por exemplo, AFLP (Amplified Fragment Length Polymorphism; polimorfismo de comprimento de fragmentos amplificados) (Vos et al., 1995 e Vos \& Kuiper, 1997) e SSR (Simple Sequence Repeats; seqüências simples repetidas ou microssatélites) (Morgante \& Olivieri, 1993). A análise de AFLP, que produz polimorfismos muito mais confiáveis e reprodutíveis que RAPDs, apresenta problemas similares de interpretação dos marcadores RAPD. Por exemplo, a origem dos marcadores é desconhecida, a designação loco/alelo não é clara e a definição de homologia das bandas é incerta. Então a análise de dados de AFLP pode ser problemática como para RAPD (Smith, 1997).

Dados de SSR, que são potencialmente fontes de valor de informação para estudos genéticos de população, tendem a ser restritos a poucos locos em um pequeno número de espécies e, embora seja demonstrada co-dominância, a homologia dos SSRs individuais é baseada no tamanho do produto e portanto ostenta as mesmas dificuldades dos RAPDs. Além disso, a natureza repetida dos locos SSR e a sua alta taxa de mutação (Orti et al., 1997 e Levinson \& Gutman, 1987) significam que não pode ser possível confirmar que bandas de tamanho idêntico em duas cultivares são homólogas, já que diferentes eventos de mutação nos SSR podem produzir tamanhos similares (Jarne \& Lagoda, 1996). É evidente a dúvida de como seria possível descrever, acessar a pureza genética e identificar cultivares baseando-se em uma lista crescente de métodos moleculares. Isso dilapidaria o enfoque de objetividade. No entanto, com os métodos atualmente utilizados, não seria apropriado esperar que todos os laboratórios utilizassem exatamente as mesmas metodologias e protocolos com o objetivo de gerar, por exemplo, exatamente os mesmos eletroforegramas para os genótipos disponíveis. Muitos laboratórios em diferentes países têm, e continuam a desenvolver e adaptar as suas próprias metodologias. O pré-requisito essencial, segundo Smith (1995), é que cada laboratório prove a habilidade de gerar resultados altamente reproduzíveis e que diferentes laboratórios possam provar a capacidade de gerar resultados com significados equivalentes, considerando similaridade ou distância entre genótipos. Dessa forma, os dados e as metodologias podem ser independentes e mutuamente avaliados e validados.

Aplicações de RAPDs na identificação de cultivares existem muitos trabalhos demonstrando resultados de identificação de cultivares com marcadores RAPD. Algo em comum entre os trabalhos é que alguns primers produzem perfis de bandas mais estáveis que outros e algumas bandas são mais estáveis que outras, sendo portanto a seleção de primers e bandas um procedimento indispensável. As condições que permitem obter repetibilidade nos resultados, normalmente demandam um trabalho minucioso e rigoroso de experimentação (Devos \& Gale, 1992), algumas vezes tedioso demais para ser concluído. A Tabela 1 apresenta uma amostra desses resultados.

Além dos resultados mostrados na Tabela 1, muitos investimentos já foram feitos no intento de adequar a técnica para incrementar a reprodutibilidade dos marcadores, buscando ajustar o método para programas de identificação de cultivares. Algumas adaptações foram feitas com sucesso pela equipe coordenada pelo professor Miller McDonald, como um protocolo de extração de DNA de sementes secas de milho, algodão, soja, amendoim, trigo e trevo-vermelho para a análise de RAPD (McDonald et al., 1994 e McDonald, 1995), com alguns resultados promissores na identificação de cultivares de soja (Jianhua et al., 1996b). Ainda, um grande número de outros trabalhos mostra a utilização de RAPDs para identificação de cultivares de diferentes espécies. Podemos citar, por exemplo, girassol (Lawson et al., 1994), banana (Kaemmer et al., 1992 e Howell et al., 1994), aipo (Yang \& Quiros, 1993), couve-flor e brócolis (Hu \& Quiros, 1991 e Kresovich et al., 1992), mamão (Stiles et al., 1993), coco (Wilde et al., 1992), cebola (Wilkie et al., 1993), algodão (Iqbal et al., 1997), cevada (Schut et al., 1997), milheto (Chowdari et al., 1998), petúnia (Cerny et al., 1996), groselha-negra (Ribes nigrum L.) (Lanham et al., 1995), crisântemo (Wolff et al., 1995), Mangifera indica L. (Schnell et al., 1995), trigo (He et al., 1992), mandioca (Colombo et al., 1998), tomate (Noli et al., 1999), batata (Ford \& Taylor, 1997), milho e soja (Jianhua et al., 1996a). Apesar de todas essas aproximações no sentido de adaptar a técnica de RAPD para a identificação de cultivares, a pesquisa não tem dirigido a atenção necessária para explicar as causas básicas do polimorfismo no padrão de bandas, resultando em estimativas muito inconsistentes.

Uma visão para o futuro - uma questão importante, colocada por Smith \& Register (1998), é se um método molecular 
TABELA 1. Exemplos de adaptações da técnica de RAPD para identificação de cultivares em algumas espécies.

\begin{tabular}{ll}
\hline \multicolumn{1}{c}{ Espécie } & \multicolumn{1}{c}{ Comentários } \\
\hline Algodão & Demonstra a possibilidade de diferenciar cultivares estreitamente Multani \& Lyon \\
(Gossipium spp.) & relacionadas através de marcadores RAPD. Melhor resolução dos (1995) \\
& $\begin{array}{l}\text { fragmentos de DNA no gel foi obtida com a utilização de nitrato de } \\
\text { prata. }\end{array}$
\end{tabular}

Cajanus cajan (L.) Millsp. Mostra a utilização de RAPDs para identificação e estimação da Ratnaparkhe et al. diversidade genética em Cajanus cajan.

\section{Canola}

(Brassica napus L.)

Canola

Castanha

(Castanea sativa Miller)

Cereais

Cynodon

Cynodon

Lilium

Lúpulo

Paeonia suffruticosa Andrews

Rosa

(Rosa spp.)
A seleção de seis primers produziu 23 bandas polimórficas variando de 300 a 2200 pares de bases, suficientes para distinguir a maioria das cultivares. Cem primers foram testados e duas cultivares, das 23 que participaram do estudo, não foram discriminadas.

Oitenta e nove bandas foram detectadas a partir de 19 primers, dos 300 primers avaliados. Seis dos melhores primers, que produziram 27 bandas polimórficas, foram selecionados para a discriminação de 37 cultivares.

Apresenta uma adaptação da técnica de RAPD para a espécie

Mailer et al.

(1994)

Mailer et al. (1997)

Galderisi et al. (1998)

Foram utilizados primers arbitrários e específicos (espaçadores dos Ko et al. genes que codificam para o RNA ribossomal 5S) para distinguir (1994) cultivares e espécies. Os primers específicos identificaram amostras de milho, cevada, sorgo, centeio, arroz, aveia e trigo, sem variação significativa dentro das espécies. Os primer arbitrários permitiram distinguir entre cultivares, mas mostraram variações dentro das cultivares. Alguns primers arbitrários produziram polimorfismos característicos das espécies.

Mostra a validade da utilização de DAF (DNA Amplification Fingerprinting) para a caracterização molecular de Cynodon.

Caetano-Anollés et al. (1995)

Dezoito cultivares de Cynodon disponíves na Austrália foram Ho et al. distinguidas por 13 primers, selecionados de 20. Alto nível de (1997) polimorfismo foi encontrado entre as cultivares.

Entre os 76 primers usados, apenas 18 (24\%) foram informativos, isto é, Yamagishi produziram fragmentos polimórficos entre as espécies e híbridos de (1995) Lilium.

Descreve a utilização RAPDs para identificação de cultivares de lúpulo. Abbott \& Fedele De 100 diferentes primers avaliados, 20-30 diferenciaram duas ou mais (1994) variedades de lúpulo. A maioria dos primers produziu somente bandas fracas e não reproduzíveis.

Dos 40 primers testados, 11 produziram 92 fragmentos de DNA Hosoki et al polimórficos, distinguindo 19 cultivares.

Cinco cultivares de rosa foram todas distinguidas pela comparação das Torres et al. diferenças nos padrões de bandas gerados por oito primers. Os primers (1993) mais discriminatórios foram opA-06 e opA-08. 


\begin{tabular}{|c|c|c|}
\hline Espécie & Comentários & Referências \\
\hline \multicolumn{3}{|l|}{... Continuação Tabela 1} \\
\hline Rosa spp. & $\begin{array}{l}\text { Vinte e cinco cultivares foram identificadas com } 2 \text { (opA-11 e opA-17), } \\
\text { selecionados a partir de } 20 \text { primers. }\end{array}$ & $\begin{array}{l}\text { Gallego \& Martinez } \\
\text { (1996) }\end{array}$ \\
\hline Soja & $\begin{array}{l}\text { Dezoito cultivares foram examinadas e dessas, apenas nove puderam ser } \\
\text { identificadas, usando dois primers (CGGCCACTGT e } \\
\text { CAGCCAACCG). }\end{array}$ & $\begin{array}{l}\text { Jianhua et al. } \\
\text { (1996b) }\end{array}$ \\
\hline Trigo & $\begin{array}{l}\text { Foi testada a habilidade da análise de RAPD em discriminar entre } 12 \\
\text { cultivares de trigo. }\end{array}$ & $\begin{array}{l}\text { Devos \& Gale } \\
(1992)\end{array}$ \\
\hline $\begin{array}{l}\text { Uva } \\
\text { (Vitis spp.) }\end{array}$ & $\begin{array}{l}\text { Foi testada a estabilidade de marcadores RAPD para identificação de } \\
\text { cultivares. Vinte e três de } 30 \text { cultivares foram identificadas com dois } \\
\text { primers (opP17 e opA09). }\end{array}$ & $\begin{array}{l}\text { This et al. } \\
\text { (1997) }\end{array}$ \\
\hline
\end{tabular}

deve refletir as diferenças relacionadas aos caracteres morfológicos tradicionais. Para isso dois pontos precisam ser considerados. Primeiro, para ter utilidade prática o método deve preferencialmente refletir a(s) característica(s) de qualidade desejada(s) pelo agricultor, pela indústria e pelo consumidor, a partir de um exame do lote de sementes. O cliente não está interessado em uma cultivar que é pura para um conjunto de marcadores moleculares, se a pureza fenotípica não corresponde com a sua expectativa. Segundo, só será possível chegar a uma correlação estreita entre diferenças morfológicas e moleculares se a distância entre os locos moleculares e os locos que formam a base genética da expressão fenotípica for bastante pequena, e se os fatores ambientais não tiverem efeito significante na expressão dos caracteres fenotípicos.

Com a análise de RAPD é praticamente impossível chegar a esse ideal. Qualquer método baseado em PCR requer uma análise separada para cada loco ou poucos locos. Um aumento da capacidade desse tipo de análise pode ser obtido somente com a automação e aumento da complexidade e tamanho dos equipamentos utilizados, mas somente as grandes companhias, em detrimento dos pequenos laboratórios, suportariam a necessidade de espaço e custo desses equipamentos. Uma tecnologia mais recente, conhecida como "DNA chip technology”, poderá resolver esse impasse. Em 1997, foram desenvolvidos pequenos "chips" com capacidade para conter séries paralelas (arrays), de centenas de milhares de sondas (seqüências de DNA homólogas aos sítios alvos) diferentes (Ramsay, 1998), que podem ser oligonucleotídeos sintéticos ou cDNAs. Com a tecnologia de DNA chips é pos- sível realizar muitos experimentos de hibridização em paralelo, investigando centenas de milhares de locos do genoma numa única análise (Wang et al., 1998). Existem vários métodos de fabricação de DNA chips, ligando as sondas (oligonucleotídeos) a um suporte sólido ou através da síntese in situ na superfície do chip (Ramsay 1998). O produto desses métodos é um DNA chip (em torno de $2 \mathrm{~cm}^{2}$ ), com desenho semelhante a um tabuleiro de xadrez de blocos microscópicos. Cada bloco é coberto por várias cópias idênticas de apenas uma das fitas do DNA que representa o segmento alvo. Assim, cada bloco pode detectar a presença ou ausência de um alelo particular de um loco. Para efetuar a análise, a amostra de DNA de um organismo ou célula, com marcador fluorescente, é desnaturada por calor (que também causa a fragmentação da amostra em pequenos pedaços) e colocada sobre o chip para incubação à baixa temperatura. Se o DNA da amostra é complementar a uma sonda no chip, aquela amostra irá hibridizar com o chip naquele bloco particular. Após um tempo suficiente, o DNA que não hibridizou com nenhum bloco é lavado, e o chip é analisado por fluorescância automaticamente sob um microscópio controlado por um computador. O programa de computador determina quais blocos detectaram seqüências complementares (representando alelos particulares ou segmentos de DNA) na amostra, e quais blocos não hibridizaram.

Tal como a análise de PCR e as suas derivações, a técnica que utiliza DNA chips, encontrará várias aplicações (Beattie, 1997; Ramsay, 1998 e Smith \& Register, 1998). Uma vantagem da utilização de DNA chips na identificação de cultivares é que será possível associar os locos com caracte- 
rísticas expressas na planta. Essa capacidade é relevante quando associada com os novos avanços na pesquisa biomolecular. Os genomas de várias espécies de plantas cultivadas estão sendo seqüenciados e a bioinformática se tornou parte integrante da biologia molecular para dar sentido à informação biológica gerada. É razoável dizer ainda, que uma rede integrada de conhecimento gerado pela pesquisa biomolecular é inevitavelmente o próximo passo da ciência. Os progressos em biologia molecular, fisiologia e bioquímica claramente apontam para uma rede de informação e conhecimento altamente interconectada. Além disso, a tendência é para ensaios experimentais de larga escala acompanhados da tecnologia computacional para o manuseio e análise dos dados e construção de modelos preditivos (Somogyi et al., 2001), baixando os custos e melhorando a acertabilidade dos ensaios.

\section{CONSIDERAÇÕES FINAIS}

Embora seja amplamente utilizada, pouco esforço tem sido feito para descrever os mecanismos moleculares que estão por trás da análise de RAPD e que podem influenciar os resultados. A despeito das dificuldades para padronização da técnica devido as sua variações intrínsecas, o fato de ter se tornado amplamente utilizada nos laboratórios pode levar a uma inevitável resolução daqueles problemas que são solvíveis e estabelecer que a análise de RAPD não é adequada para certas aplicações. Mesmo no mapeamento genômico, a análise de RAPD seria mais útil como uma ferramenta meio, para explorações iniciais, e não uma ferramenta conclusiva como marcador. Por isso, a técnica de RAPD parece encontrar maior utilidade em análises genéticas iniciais de uma espécie não caracterizada. Com esta técnica é possível escanear o genoma inteiro para obter um conjunto de marcadores polimórficos de DNA. Inicia-se com vários primers construídos aleatoriamente e testa-se cada um isoladamente para amplificar um conjunto de locos, casualmente detectados, de um conjunto de indivíduos. Cada loco polimórfico detectado como uma banda presente em alguns indivíduos, mas não em outros, podem ser isoladas e clonadas para outras análises. Na análise de genótipos procura-se extensivamente detectar mudanças unitárias de bases, considerando que esta é a forma mais comum de polimorfismo de DNA. A maioria dos problemas associados com a análise de RAPD pode ser resumida como problemas associados com a reprodutibilidade e homologia dos produtos. Se esses problemas podem ser efetivamente resolvidos então a análise de RAPD pode se tornar um método eficiente e aplicável para identificação de cultivares. Infelizmente, o tempo e os recursos necessários para resolver o primeiro problema e a dificuldade de entendimento da base do segundo, torna a técnica inapropriada para utilização direta em testes de identificação de cultivares e proteção da propriedade intelectual.

A reprodutibilidade dos produtos é determinada por uma variedade de fatores e é influenciada pelas condições individuais de cada laboratório. Mudanças que resultam da escolha da DNA polimerase e do termociclador tornam a repetição de experimentos entre laboratórios problemática, e torna questionável o valor futuro de qualquer marcador identificado pela análise de RAPD. Essas críticas não são para dizer que a análise de RAPD não tem utilidade para identificação de cultivares. No entanto, investigações usando RAPDs não podem ser empreendidas em um vácuo científico e biológico, e se tais marcadores são para ser utilizados então eles precisam ser baseados em um entendimento da biologia do organismo estudado. Novos paradigmas e métodos serão necessários para fazer a crítica transição do conhecimento para o entendimento.

Com o recente avanço no seqüenciamento dos genomas das espécies cultivadas, espera-se o desenvolvimento de novas técnicas que permitam a automação do processo de identificação de cultivares. Um exemplo seria a utilização de DNA chips, que contendo centenas de milhares de seqüências de DNA independentes, poderá elevar grandemente a capacidade de detecção e comparação de inúmeros polimorfismos entre os diferentes genótipos.

\section{REFERÊNCIAS}

ABBOTT, M.S. \& FEDELE, M.J. A DNA-based varietal identification procedure for hop leaf tissue. Journal of the Institute of Brewing, Berlin, v.100, n.4, p.283-285, 1994.

ARRIBAS, R.; TÒRTOLA, S.; WELSH, J.; McCLELLAND, M. \& PEINADO, M.A. Arbitrarily primed PCR and RAPDs. In: MICHELI, M.R. \& BOVA, R. (eds.). Fingerprinting methods based on arbitrarily primed PCR. Berlin: Springer-Verlag, 1997. p.47-53.

AYLIFFE, A.A.; LAWRANCE, G.D.; ELLIS, J.G. \& PRYOR, A.J. Heteroduplex molecules formed between allelic sequences cause nonparental RAPD bands. Nucleic Acids Research, Oxford, v.22, n.9, p.1632-1636, 1994.

BEATTIE, K.L. Genomic fingerprinting using oligonucleotide arrays. In: CAETANO-ANOLLÉS, G. \& GRESSHOFF, P.M. (eds.) DNA markers: protocols, applications and overviews. New York: Wiley-Liss, 1997. p.213-224.

BEYERMANN, B.; NÜRNBERG, P.; WEIHE, A.; MEIXNER, M.; EPPLEN, J.T. \& BÖRNER, T. Fingerprinting plant genomes with oligonucleotide probes specific for simple repetitive DNA sequences. Theoretical and Applied Genetics, Berlin, v.83, n.6/7, p.691-694, 1992. 
CAETANO-ANOLLÉS, G. Recovering amplified DNA from silver stained gels. In: MICHELI, M.R \& BOVA, R. (eds.). Fingerprinting methods based on arbitrarily primed PCR. Berlin: Springer-Verlag, 1997a. p.153-160.

CAETANO-ANOLLÉS, G. Resolving DNA amplification products using polyacrylamide gel electrophoresis and silver staining. In: MICHELI, M.R. \& BOVA, R. (eds.). Fingerprinting methods based on arbitrarily primed PCR. Berlin: SpringerVerlag, 1997b. p.119-134.

CAETANO-ANOLLÉS, G.; BASSAM, B.J. \& GRESSHOFF, P.M. DNA amplification fingerprinting using very short arbitrary oligonucleotide primers. Bio Technology, New York, v.9, n.6, p.553-557, 1991

CAETANO-ANOLLÉS, G.; BASSAM, B.J. \& GRESSHOFF, P.M. DNA amplification fingerprinting with very short primers. In: SYMPOSIUM ON APPLICATIONS OF RAPD TECHNOLOGY TO PLANT BREEDING, 1, Minneapolis, $1^{\circ}$ nov. 1992. Anais. Minneapolis: Crop Science Society of America/ American Society for Horticultural Science/American Genetic Association, 1992. p.18-25.

CAETANO-ANOLLÉS, G.; CALLAHAN, L.M.; WILLIAMS, P.E.; WEAVER, K.R. \& GRESSHOFF, P.M. DNA amplification fingerprinting analysis of bermudagrass (Cynodon): genetic relationships between species and interspecific crosses. Theoretical and Applied Genetics, Berlin, v.91, n.2, p.228$235,1995$.

CERNY, T.A.; CAETANO-ANOLLÉS, G.; TRIGIANO, R.N. \& STARMAN, T.W. Molecular phylogeny and DNA amplification fingerprinting of Petunia taxa. Theoretical and Applied Genetics, Berlin, v.92, n.8, p.1009-1016, 1996.

CHOWDARI, K.V; DAVIERWALA, A.P. GUPTA, V.S. RANJEKAR, P.K. \& GOVILA, O.P. Genotype identification and assessment of genetic relationships in pearl millet (Pennisetum glaucum (L.) R.Br) using microsatellites and RAPDs. Theoretical and Applied Genetics, Berlin, v.97, n.1/ 2, p.154-162, 1998.

COLOMBO, C.; SECOND, G.; VALLE, T.L. \& CHARRIE, A. Genetic diversity characterization of cassava cultivars (Manihot esculenta Crantz). I. RAPD markers. Genetics and Molecular Biology, Ribeirão Preto, v.21, n.1, p.105-113, 1998.

DEVOS, K.M. \& GALE, M.D. The use of random amplified polymorphic DNA markers in wheat. Theoretical and Applied Genetics, Berlin, v.84, n.5/6, p.567-572, 1992.

DICE, L.R. Measures of the amount of ecological association between species. Journal of Ecology, Chicago, v.26, n.3, p.297-302, 1945

DUARTE, J.M.; SANTOS, J.B. \& MELO, L.C. Comparison of similarity coefficients based on RAPD markers in the common bean. Genetics and Molecular Biology, Ribeirão Preto, v.22, n.3, p.427-432, 1999.

DWEIKAT, I. \& MACKENZIE, S. Denaturing gradient gel electrophoresis for enhanced detection of DNA polymorphisms. In: MICHELI, M.R. \& BOVA, R. (eds.). Fingerprinting methods based on arbitrarily primed PCR. Berlin: SpringerVerlag, 1997. p.135-141.
DWEIKAT, I.M. \& MACKENZIE, S.A. RAPD-DGGE: applications to pedigree assessment, cultivar identification and mapping. In: CAETANO-ANOLLÉS, G. \& GRESSHOFF, P.M. (eds.). DNA markers: protocols, applications, and overviews. New York: Wiley-Liss, 1997. p.85-90.

ELLSWORTH, D.L; RITTENHOUSE, K.D. \& HONGTRAKUL, V. Artifactual variation in randomly amplified polimorphic DNA banding pattern. Biotechniques, Westborough, v.14, n.2, p.214-217, 1993.

FERREIRA, M.E. \& GRATTAPAGLIA, D. Introdução ao uso de marcadores moleculares em análise genética. Brasília: Embrapa/Cenargen, 1996. 220p.

FORD, R. \& TAYLOR, P.W.J. The application of RAPD markers for potato cultivar identification. Australian Journal of Agricultural Research, Collingwood Victoria, v.48, n.8, p.1213-1217, 1997 .

FRITSCH, P.; HANSON, M.A.; SPORE, C.D.; PACK, P.E. \& RIESEBERT, L.H. Constancy of RAPD primer amplification strength among distantly related taxa of flowering plants. Plant Molecular Biology Reporter, Tucson, v.11, n.1, p.10-20, 1993.

GALDERISI, U.; CIPOLLARO, M.; DI BERNARDO, G.; DE MASI, L.; GALANO, G. \& CASCINO, A. Molecular typing of Italian sweet chestnut cultivars by random amplified polymorphic DNA analysis. Journal of Horticultural Science \& Biotechnology, Ashford, v.73, n.2, p.259-263, 1998.

GALLEGO, F.J. \& MARTINEZ, I. Molecular typing of rose cultivars using RAPDs. Journal of Horticultural Science, Ashford, v.71, n.6, p.901-908, 1996.

GRATTAPAGLIA, D. \& SEDEROFF, R. Genetic linkage maps of Eucalyptus grandis and E. urophylla using a pseudo-testcross strategy and RAPD markers. Genetics, Stanford, v.137, n.4, p.1121-1137, 1994.

HALLDÉN, C.; HANSEN, M.; NILSSON, N.O.; HJERDIN, A. \& SÄLL, T. Competition as a source of errors in RAPD analysis. Theoretical and Applied Genetics, Berlin, v.93, n.8, p.11851192, 1996.

HANSEN, M.; HALLDÉN, C. \& SÄLL, T. Error rates and polymorphism frequencies for three RAPD protocols. Plant Molecular Biology Reporter, Tucson, v.16, n.2, p.139-146, 1998

HE, S.; OHM, H. \& MACKENZIE, S. Detection of DNA sequence polymorphisms among wheat varieties. Theoretical and Applied Genetics, Berlin, v.84, n.5/6, p.573-578, 1992.

HEUN, M. \& HELENTJARIS, T. Inheritance of RAPDs in F1 hybrids of corn. Theoretical and Applied Genetics, Berlin, v.85, n.8, p.961-968, 1993.

HILLIS, D.M. Homology in molecular biology. In: HALL, B.K. (ed.) Homology: the hierarchical basis of comparative biology. London: Academic Press, 1994. p.339-368.

HO, C.Y.; MCMAUGH, S.J.; WILTON, A.N.; MCFARLANE, I.J. \& MACKINLAY, A.G. DNA amplification variation within cultivars of turf-type couch grasses (Cynodon ssp.). Plant Cell Reports, Berlin, v.16, n.11, p.797-801, 1997. 
HOSOKI, T.; KIMURA, D.; HASEGAWA, R.; NAGASAKO, T.; NISHIMOTO, K · OHTA, K · SUGIYAMA, M \& HARUKI, $\mathrm{K}$. Comparative study of Chinese tree peony cultivars by random amplified polymorphic DNA (RAPD) analysis. Scientia Horticulturae, Oxford, v.70, n.1, p.67-72, 1997.

HOWELL, E.C.; NEWBURY, H.J.; SWENNEN, R.L.; WITHERS, L.A. \& FORD-LLOYD, B.V. The use of RAPD for identifying and classifying Musa germplasm. Genome, Berlin, v.37, n.2, p.328-332, 1994.

HU, J. \& QUIROS, C.F. Identification of broccoli and cauliflower cultivars with RAPD markers. Plant Cell Reports, Berlin, v.10, n.10, p.505-511, 1991 .

IQBAL, M.J.; AZIZ, N.; SAEED, N.A.; ZAFAR, Y. \& MALIK, K.A. Genetic diversity evaluation of some elite cotton varieties by RAPD analysis. Theoretical and Applied Genetics, Berlin, v.94, n.1, p.139-144, 1997.

JACCARD, P. Nouvelles recherches sur la distribution florale. Bulletin de la Société Vaudense des Sciences Naturelles, v.44, p.223-270, 1908 .

JARNE, P. \& LAGODA, P.J.L. Microsatellites, from molecules to populations and back. Trends in Ecology and Evolution, New York, v.11, n.3, p.424-430, 1996.

JIANHUA, Z.; McDONALD, M.B. \& SWEENEY, P.M. Random amplified polymorphic DNA (RAPDs) from seeds of differing soybean and maize genotypes. Seed Science and Technology, Zürich, v.24, n.3, p.513-522, 1996a.

JIANHUA, Z.; McDONALD, M.B. \& SWEENEY, P.M. Soybean cultivar identification using RAPD. Seed Science and Technology, Zürich, v.24, n.3, p.589-592, 1996b.

KAEMMER, D; AFZA, R ; WEISING, K ; KAHL, G. \& NOVAK, F.J. Oligonucleotide and amplification fingerprinting of wild species and cultivars of banana (Musa spp.). Bio Technology, New York, v.10, n.9, p.1030-1035, 1992.

KARP, A. \& EDWARDS, K.J. DNA markers: a global overview. In CAETANO-ANOLLÉS, G. \& GRESSHOFF, P.M. (eds.). DNA markers: protocols, applications, and overviews. New York: Wiley-Liss, 1997. p.1-13.

KAZAN, K.; MANNERS, J.M. \& CAMERON, D.F. Genetic variation in agronomically important species of Stylosanthes determined using random amplified polymorphic DNA markers. Theoretical and Applied Genetics, Berlin, v.85, n.6 7, p.882-888, 1993.

KO, H.L.; HENRY, R.J.; GRAHAM, G.C.; FOX, G.P.; CHADBONE, D.A. \& HAAK, I.C. Identification of cereals using the polymerase chain reaction. Journal of Cereal Science, San Diego, v.19, n.1, p.101-106, 1994.

KRESOVICH, S.; WILLIAMS, J.G.K.; MCFERSON, J.R.; ROUTMAN, E.J. \& SCHAAL, B.A. Characterization of genetic identities and relationships of Brassica oleracea L. via a random amplified polymorphic DNA assay. Theoretical and Applied Genetics, Berlin, v.85, n.2/3, p.190-196, 1992.

LANHAM, P.G.; BRENNAN, R.M.; HACKETT, C. \& MCNICOL, R.J. RAPD fingerprinting of blackcurrant (Ribes nigrum L.) cultivars. Theoretical and Applied Genetics, Berlin, v.90, n.2, p.166-172, 1995
LAWSON, W.R.; HENRY, R.J.; KOCHMAN, J.K. \& KONG, G.A Genetic diversity in sunflower (Helianthus annuus L.) as revealed by random amplified polymorphic DNA analysis. Australian Journal of Agricultural Research, Collingwood Victoria, v.45, n.7, p.1319-1327, 1994.

LEVINSON, G. \& GUTMAN, G.A. High frequency of short frameshifts in poly-GA/GT tandem repeats borne by bacteriophage M13 in Eschirichia coli K12. Nucleic Acids Research, Oxford, v.15, n.13, p.5323-5338, 1987.

MAILER, R.J.; SCARTH, R. \& FRISTENSKY, B. Discrimination among cultivars of rapeseed (Brassica napus L.) using DNA polymorphisms amplified from arbitrary primers. Theoretical and Applied Genetics, Berlin, v.87, n.6, p.697-704, 1994

MAILER, R.J.; WRATTEN, N. \& VONARX, M. Genetic diversity amongst Australian canola cultivars determined by randomly amplified polymorphic DNA. Australian Journal of Experimental Agriculture, Collingwood Victoria, v.37, n.7, p.793-800, 1997.

MARCOS-FILHO, J. \& McDONALD, M.B. Sensitivity of RAPD analysis, germination and vigour tests to detect the intensity of deterioration of naturally and artificially aged soybean seeds. Seed Science and Technology, Zürich, v.26, n.1, p.141-157, 1998.

McDONALD, M.B. Genetic purity: from protein electrophoresis to RAPDs. Proceedings of the Fiftieth Annual Corn \& Sorghum Industry Research Conference, Washington, p.256271, 1995.

McDONALD, M.B.; ELLIOT, L.J. \& SWEENEY, P.M. DNA extraction from dry seeds for RAPD analyses in varietal identification studies. Seed Science and Technology, Zürich, v.22, n.1, p.171-176, 1994.

MENG, X.; MA, H.; ZHANG, W. \& WANG, D. A fast procedure for genetic purity determination of head Chinese cabbage hybrid seed based on RAPD markers. Seed Science and Technology, Zürich, v.26, n.6, p.829-833, 1998.

MOORE, G. \& GUSTAFSON, J.P. Comparative analysis of cereal genomes. In: CAETANO-ANOLLÉS, G. \& GRESSHOFF, P.M. (eds.). DNA markers: protocols, applications, and overviews. New York: Wiley-Liss, 1997. p.259-270.

MORGANTE, M. \& OLIVIERI, A.M. PCR-amplified microsatellites as markers in plant genetics. The Plant Journal, Oxford, v.3, n.1, p.175-182, 1993.

MULTANI, D.S. \& LYON, B.R. Genetic fingerprinting of Australian cotton cultivars with RAPD markers. Genome, Berlin, v.38, n.5, p.1005-1008, 1995.

NEI, M. \& LI, W. Mathematical model for studying genetic variation in terms of restriction endonucleases. Proceedings of the National Academy of Sciences of the USA, Washington, v.76, p.5269-5273, 1979 .

NOLI, E.; CONTI, S.; MACCAFERRI, M. \& SANGUINETI, M.C Molecular characterization of tomato cultivars. Seed Science and Technology, Zürich, v.27, n.1, p.1-10, 1999.

NOVY, R.G. \& VORSA, N. Evidence for RAPD heteroduplex formation in cranberry: implications for pedigree and geneticrelatedness studies and a source of co-dominant RAPD markers. 
Theoretical and Applied Genetics, Berlin, v.92, n.7, p.840849, 1996a.

NOVY, R.G. \& VORSA, N. Identifying genotypic heterogeneity in 'McFarlin' cranberry: a randomly-amplified polymorphic DNA (RAPD) and phenotypic analysis. Journal of the Americam Society of Horticultural Science, Alexandria, v.121, n.2, p.210-215, 1996b.

ORTI, G.; PEARSE, D.E. \& AVISE, J.C. Phylogenetic analysis of length variation at a microsatellite loco. Proceedings of the National Academy of Sciences of the USA, Washington, v.94, p.10745-10749, 1997.

PENNER, G.A. RAPD analysis of plant genomes. In: JAUHAR, P.P. (ed.). Methods of genome analysis in plants. Boca Raton: CRC Press, 1996. p.251-268.

PENNER, G.A.; BUSH, A.; WISE, R.; KIM, W.; DOMIER, L.; KASHA, K.; LAROCHE, A.; SCOLES, G.; MOLNAR, S.J. \& FEDAK, G. Reproducibility of random amplified polymorphic DNA (RAPD) analysis among laboratories. PCR Methods Applic., v.2, p.341-345, 1993.

RAFALSKI, A.; TINGEY, S. \& WILLIAMS, J.G.K. Random amplified polymorphic DNA (RAPD) markers. In: GELVIN, S.B. \& SCHILPEROORT, R.A. (eds.) Plant molecular biology manual. Belgium: Kluwer Academic Publishers, 1994. p.1-8.

RAFALSKI, J.A. Randomly amplified polymorphic DNA (RAPD) analysis. In: CAETANO-ANOLLES, G. \& GRESSHOFF, P.M. (eds.). DNA markers: protocols, applications and overviews. New York: Wiley-Liss, 1997. p.75-83.

RAMSAY, G. DNA chips: state of the art. Nature Biotechnology, New York, v.16, n.1, p.40-44, 1998.

RATNAPARKHE, M.B.; GUPTA, V.S.; VEN MURTHY, M.R. \& RANJEKAR, P.K. Genetic fingerprinting of pigeonpea Cajanus cajan (L.) Millsp. and its wild relatives using RAPD markers. Theoretical and Applied Genetics, Berlin, v.91, n.6/7, p.893$898,1995$.

SAITOU, N. \& NEI, M. The Neighbor-Joining method: a new method for reconstructing phylogenetic trees. Molecular Biology and Evolution, v.4, n.3, v.406-425, 1987.

SCHNELL, R.J.; RONNING, C.M. \& KNIGHT, R.J.Jr. Identification of cultivars and validation of genetic relationships in Mangifera indica L. using RAPD markers. Theoretical and Applied Genetics, Berlin, v.90, n.2, p.269-274, 1995.

SCHUT, J.W; QI, X. \& STAM, P. Association between relationship measures based on AFLP markers, pedigree data and morphological traits in barley. Theoretical and Applied Genetics, Berlin, v.95, n.7, p.1161-1168, 1997

SKROCH, P. \& NIENHUIS, J. Impact of scoring error and reproducibility of RAPD data on RAPD based estimates of genetic distance. Theoretical and Applied Genetics, Berlin, v.91, n.6/7, p.1086-1091, 1995.

SKROCH, P.; TIVANG, J. \& NIENHUIS, J. Analysis of genetic relationships using RAPD marker data. In: SYMPOSIUM ON APPLICATIONS OF RAPD TECHNOLOGY TO PLANT BREEDING, 1, Minneapolis, 1 nov. 1992. Anais. Minneapolis:
Crop Science Society of America/American Society for Horticultural Science/American Genetic Association, 1992. p.26-30.

SMITH, J.S.C. Identification of cultivated varieties by nucleotide analysis. In: WRIGLEY, C.W. (ed.). Identification of foodgrain varieties. St.Paul: American Association of Cereal Chemists, 1995. p.131-150.

SMITH, J.S.C. \& REGISTER, J.C. Genetic purity and testing technogies for seed quality: a company perspective. Seed Science Research, New York, v.8, n.2, p.285-293, 1998.

SMITH, S. Cultivar identification and varietal protection. In: CAETANO-ANOLLÉS, G. \& GRESSHOFF, P.M. (eds.). DNA markers: protocols, applications, and overviews. New York: Wiley-Liss, 1997. p.283-299.

SMITH, S. \& CHIN, E. The utility of random primer-mediated profiles, RFLPs, and other technologies to provide useful data for varietal protection. In: SYMPOSIUM ON APPLICATIONS OF RAPD TECHNOLOGY TO PLANT BREEDING, 1, Minneapolis, 1 nov. 1992. Anais. Minneapolis: Crop Science Society of America/American Society for Horticultural Science/ American Genetic Association, 1992. p.46-49.

SNEATH, P.H.A. \& SOKAL, R.R. Numerical taxonomy. San Francisco: Freeman. 1973. 573p.

SOMOGYI, R.; FUHRMAN, S. \& WEN, X. Genetic network inference in computational models and applications to largescale gene expression data. In: BOWER, J.M. \& BOLOURI, H. (eds.). Computational modeling of genetic and biochemical networks. Cambridge: MIT Press, 2001. p.119-157.

STILES, J.I.; LEMME, C.; SONDUR, S.; MORSHIDI, M.B. \& MANSHARDT, R. Using randomly amplified polymorphic DNA for evaluating genetic relationships among papaya cultivars. Theoretical and Applied Genetics, Berlin, v.85, n.6/ 7, p.697-701, 1993.

THIS, P.; CUISSET, C. \& BOURSIQUOT, J.M. Development of stable RAPD markers for the identification of grapevine rootstocks and the analysis of genetic relationships. American Journal of Enology and Viticulture, v.48, n.4, p.492-501, 1997.

THORMANN, C.E. \& OSBORN, T.C. Use of RAPD and RFLP markers for germplasm evaluation. In: SYMPOSIUM ON APPLICATIONS OF RAPD TECHNOLOGY TO PLANT BREEDING, 1, Minneapolis, $1^{\circ}$ nov. 1992. Anais. Minneapolis: Crop Science Society of America/American Society for Horticultural Science/American Genetic Association, 1992. p.9-11.

TINGEY, S.V.; RAFALSKI, J.A. \& WILLIAMS, J.G.K. Genetic analysis with RAPD markers. In: SYMPOSIUM ON APPLICATIONS OF RAPD TECHNOLOGY TO PLANT BREEDING, 1, Minneapolis, 1 nov. 1992. Anais. Minneapolis: Crop Science Society of America/American Society for Horticultural Science/American Genetic Association, 1992. p.3-8.

TORRES, A.M.; MILLAN, T. \& CUBERO, J.I. Identifying rose cultivars using random amplified polymorphic DNA markers. Hortscience, Alexandria, v.28, n.4, p.333-334, 1993. 
VOS, P.; HOGERS, R.; BLEEKER, M.; REIJANS, M.; VAN DE LEE, T.; HORNES, M.; FRIJTERS, A.; POT, J.; PELEMAN, J.; KUIPER, M. \& ZABEAU, M. AFLP: a new technique for DNA fingerprinting. Nucleic Acids Research, Oxford, v.23, n.21, p.4407-4414, 1995

VOS, P. \& KUIPER, M. AFLP analysis. In: CAETANO-ANOLLÉS, G. \& GRESSHOFF, P.M. (eds.). DNA markers: protocols, applications, and overviews. New York: Wiley-Liss, 1997. p.115-131

WANG, D.G.; FAN, J.B.; SIAO, C.J.; BERNO, A.; YOUNG, P.; SAPOLSKY, R.; GHANDOUR, G.; PERKINS, N.; WINCHESTER, E.; SPENCER, J.; KRUGLYAK, L.; STEIN, L ; HSIE, L; TOPALOGLOU, T; HUBBELL, E; ROBINSON, E.; MITTMANN, M.; MORRIS, M.S.; SHEN, N.; KILBURN, D.; RIOUX, J.; NUSBAUM, C.; ROZEN, S.; HUDSON, T.J. \& LANDER, E.S. Large-scale identification, mapping, and genotyping of single-nucleotide polymorphisms in the human genome. Science, Washington, v.280, p.1077-1082, 1998.

WEEDEN, N.F. Inheritance and reliability of RAPD markers. In: SYMPOSIUM ON APPLICATIONS OF RAPD TECHNOLOGY TO PLANT BREEDING, 1, Minneapolis, $1^{\circ}$ nov. 1992. Anais. Minneapolis: Crop Science Society of America/ American Society for Horticultural Science/American Genetic Association, 1992. p.12-17.

WELSH, J. \& McCLELLAND, M. Fingerprinting genomes using PCR with arbitrary primers. Nucleic Acids Research, Oxford, v.18, n.24, p.7213-7218, 1990.

WILDE, J.; WAUGH, R. \& POWELL, W. Genetic fingerprinting of Theobroma clones using randomly amplified polymorphic
DNA markers. Theoretical and Applied Genetics, Berlin, v.83, n.6/7, p.871-877, 1992.

WILKIE, S.E.; ISSAC, P.G. \& SLATER, R.J. Random amplified polymorphic DNA (RAPD) markers for genetic analysis in Allium. Theoretical and Applied Genetics, Berlin, v.86, n.4, p.497-504, 1993.

WILLIAMS, J.G.K.; KUBELIK, A.R.; LIVAK, K.J.; RAFALSKI, J.A. \& TINGEY, S.V. DNA polymorphisms amplified by arbitrary primers are useful as genetic markers. Nucleic Acids Research, Oxford, v.18, n.22, p.6531-6535, 1990.

WILLIAMS, J.G.K; RAFALSKI, J.A. \& TINGEY, S. Genetic analysis using random amplified polymorphic DNA markers. Methods in Enzymology, v.218, pt.1, p.704-740, 1993.

WOLFF, K.; ZIETKIEWICZ, E. \& HOFSTRA, H. Identification of chrysanthemum cultivars and stability of DNA fingerprint patterns. Theoretical and Applied Genetics, Berlin, v.91, n.3, p.439-447, 1995.

WRIGLEY, C.W. \& BATEY, I.L. Efficient strategies for variety identification. In: WRIGLEY, C.W. (ed.). Identification of food-grain varieties. St.Paul: American Association of Cereal Chemists, 1995. p.19-33.

YAMAGISHI, M. Detection of section-specific rendom amplified polymorphic DNA (RAPD) markers in Lilium. Theoretical and Applied Genetics, Berlin, v.91, n.6/7, p.830-835, 1995.

YANG, X. \& QUIROS, C.F. Identification and classification of celery cultivars with RAPD markers. Theoretical and Applied Genetics, Berlin, v.86, n.2/3, p.205-212, 1993 